\title{
Livros
}

\section{Better Mental Health Care}

Graham Thornicroft and Michele Tansella. Reino Unido: Cambridge University Press; 2009. 184p. ISBN 978-0-521-68946-5.

Os professores Thornicroft (Reino Unido) e Tansella (Itália) nos apresentam, em linguagem mais acessível e com incorporação de novas evidências de pesquisas, a partir do livro anterior (The Mental Health Matrix, 1999) um guia consistente para o desenvolvimento e avaliação dos serviços comunitários de saúde mental. Devese pautar pelo atendimento perto de casa, quebra do ciclo de exclusão e busca do melhor cuidado, aliados à evidência clínica (pesquisas, linhas guias, protocolos), à experiência acumulada, à ética e à luta contra o estigma da doença mental. As propostas se engendram num plano de ação/avaliação, o "modelo matricial", com duas dimensões: tempo (estrutura, processo e resultados)

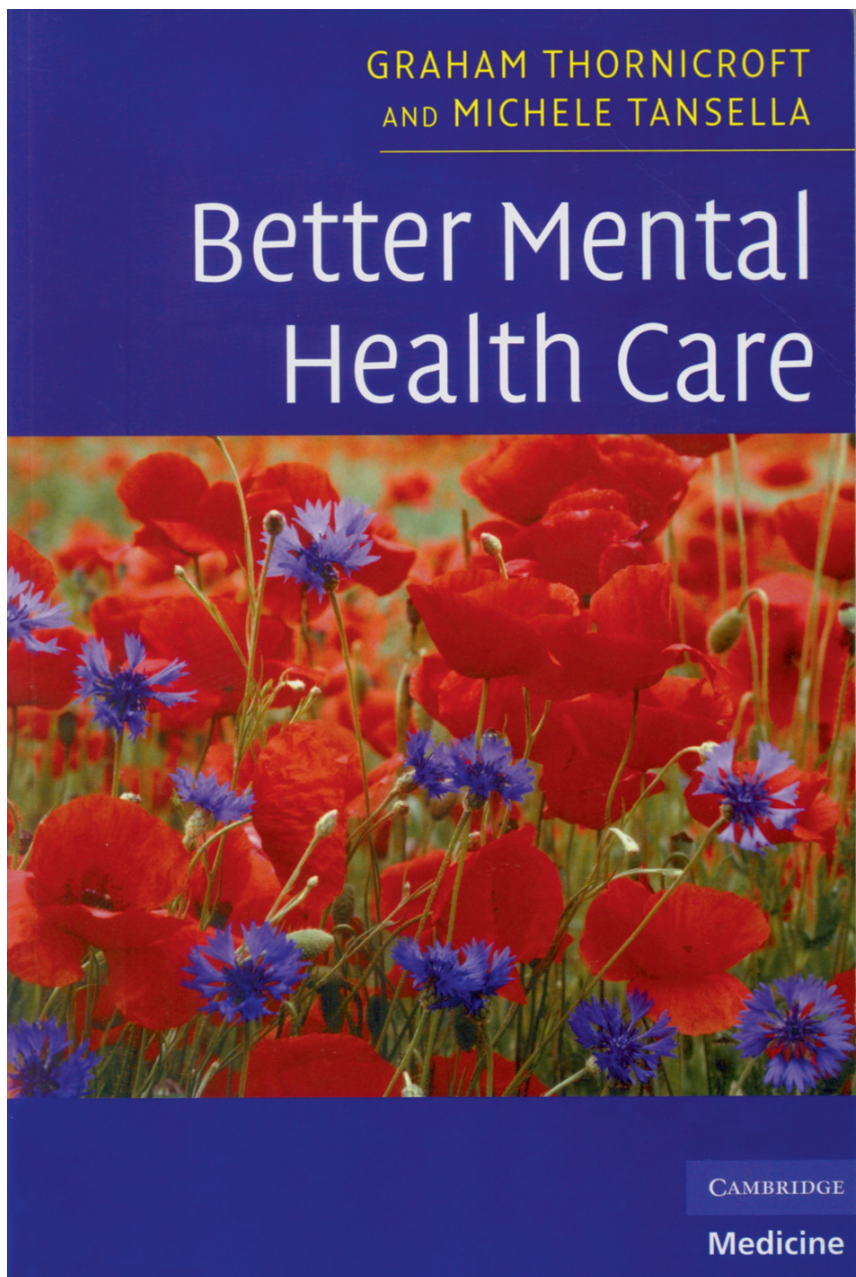

e lugar (nacional/regional, local e individual), e na vocação dos serviços em se articularem com a comunidade, usuários, familiares, profissionais, planejadores, elaboradores e provedores de políticas públicas, pesquisadores e outros.

O prefácio do professor Benedetto Saraceno (OMS) enriquece os 14 capítulos, o mapa da trilha, bem organizado e articulado ao momento histórico global da "reforma dos serviços de saúde mental", independentemente do nível de desenvolvimento político-social, cultural e econômico dos países. Nessa rota são fundamentais equipes capacitadas, o que é particularmente abordado no capítulo 13. Os pontos-chave, as referências ao término de cada capítulo, e o índice ao final do livro são muito úteis. Ultrapassa-se a barreira da experiência do oeste europeu pela colaboração de centros de 25 países (Brasil inclusive) de todas as regiões.

Apesar do extremo impacto social da doença mental, mais do que as outras, ela permanece com tratamento insuficiente no mundo todo, e o investimento é proporcionalmente menor; cotidianamente, recursos são alocados de modo impróprio, em serviços/instituições de baixa efetividade e falta de pessoal capacitado.

Nesses 50 anos do Mental Health Act no Reino Unido, as ideias do livro se apresentam como referência abrangente para as redes de serviços de cuidados comunitários em saúde mental, para todos os níveis de desenvolvimento regional/nacional e local. Em nosso país, de recursos parcos para a saúde - e menor ainda para a saúde mental -, devemos bater-nos por serviços mais eficientes e evidenciados nos melhores resultados da pesquisa. Incorporarmos nas ações os direitos humanos, a eficiência no planejamento e nos investimentos e a participação total da comunidade. Lutamos pela garantia da transferência dos recursos intra-hospitalares desativados para os serviços comunitários (CAPS e outros). Ainda, da leitura depreende-se que precisamos de todos os tipos de serviços que satisfaçam as reais necessidades de uma rede completa de atenção comunitária, que busque alternativas para soluções específicas locais, sob a ótica do melhor cuidado e da avaliação, e menos das certezas programáticas, ou dogmáticas. Às universidades, a tarefa de capacitação das equipes, de transferência dos resultados de pesquisas, do envolvimento direto no debate e na consolidação de uma rede de serviços efetiva, eficiente, acessível, compreensiva, equitativa, autônoma e sem solução de continuidade do intra ao extra-hospitalar.

O livro é fundamental para estudantes, médicos, psiquiatras, toda a equipe; para os usuários de serviços, familiares e suas associações; é um convite ao fortalecimento do movimento contra o estigma da doença mental, e pela garantia dos direitos humanos e político-sociais dos doentes.

Thornicroft é pesquisador militante da chamada psiquiatria comunitária, com extensão para vários países e, recentemente, com participação marcante no plano nacional de saúde mental para os próximos 10 anos na Inglaterra. Estará neste ano no XXVII Congresso da ABP.

Guilherme Gregório Universidade Federal de São Paulo (Unifesp), São Paulo (SP), Brasil 